OPEN ACCESS

Edited by:

Małgorzata Wierzbicka

Poznan University of Medical

Sciences, Poland

Reviewed by:

Anna Fialová,

SOTIO a.s., Czechia

Jose Angelito Ugalde Hardillo,

Erasmus Medical Center, Netherlands

*Correspondence:

Kyung Tae

kytae@hanyang.ac.kr

Specialty section

This article was submitted to

Otorhinolaryngology - Head and Neck

Surgery,

a section of the journal

Frontiers in Surgery

Received: 10 December 2021 Accepted: 29 December 2021

Published: 21 January 2022

Citation:

Jun HW, Ji YB, Song CM, Myung JK Park HJ and Tae K (2022) Positive Rate of Human Papillomavirus and lts Trend in Head and Neck Cancer in

South Korea. Front. Surg. 8:833048

doi: 10.3389/fsurg.2021.833048

\section{Positive Rate of Human Papillomavirus and Its Trend in Head and Neck Cancer in South Korea}

\author{
Hyun Woong Jun ${ }^{1}$, Yong Bae $\mathrm{Ji}^{1}$, Chang Myeon Song ${ }^{1}$, Jae Kyung Myung ${ }^{2}$, Hae Jin Park ${ }^{3}$ \\ and Kyung Tae ${ }^{1 *}$
}

${ }^{1}$ Department of Otolaryngology-Head and Neck Surgery, College of Medicine, Hanyang University, Seoul, South Korea, ${ }^{2}$ Department of Pathology, College of Medicine, Hanyang University, Seoul, South Korea, ${ }^{3}$ Department of Radiation Oncology, College of Medicine, Hanyang University, Seoul, South Korea

Introduction: This study aimed to investigate the positive rate of human papillomavirus (HPV) and its trend in head and neck squamous cell carcinoma (HNSCC) in South Korea and to evaluate the clinical differences between HPV-positive and -negative tumors.

Methods: We studied 300 patients with HNSCC arising in the oropharynx ( $n=77)$, oral cavity $(n=65)$, larynx $(n=106)$, hypopharynx $(n=40)$, and sinonasal cavity $(n=12)$, treated in a tertiary university hospital in South Korea from January 2008 to July 2020. HPV status was determined using p16 immunohistochemical staining of formalin-fixed paraffin-embedded tissues.

Results: Of the 300 patients with HNSCC, the positive rate of p16 was $30.3 \%$ (91/300). The p16 positive rate was $70.1,13.9,20.8,15$, and $0 \%$ in the oropharynx, oral cavity, larynx, hypopharynx, and sinonasal cavity, respectively. HPV-positive oropharyngeal squamous cell carcinoma (OPSCC) patients were significantly younger than HPV-negative OPSCC patients. The positive rate of HPV in OPSCC has increased over time from 2008 to 2020, but has not changed significantly in the other primary sites. The disease-free survival curve of HPV-positive OPSCC was significantly better than that of HPV-negative tumors.

Conclusion: The positive rate of HPV in Korean patients with OPSCC is significantly high $(70.1 \%)$, similar to that in North America and Europe, and has increased abruptly in the past 12 years.

Keywords: human papillomavirus, head and neck cancer, squamous cell carcinoma, oropharyngeal cancer, prevalence

\section{INTRODUCTION}

Traditionally, smoking and alcohol drinking have been known to be major causes of head and neck squamous cell carcinoma (HNSCC). Recently, human papillomavirus (HPV) infection emerged as an important cause of HNSCC, especially for oropharyngeal squamous cell carcinoma (OPSCC) (1-5). 
HPV is a double-stranded DNA virus that causes abnormal cell proliferation and genomic instability (6). HPV acts as a carcinogen in the cervix, vulva, vagina, penis, anus, and the oropharynx. HPV for head and neck cancer was reported first in 1983 (7). In 2007, the International Agency for Research on Cancer (IARC) recognized HPV as a carcinogen for HNSCC (4). Of more than 200 types of HPV, the most common highrisk type HPV for HNSCC is type 16, followed by type 33 and type 18 (8). As HPV infection is mostly sexually transmitted, an increasing number of HPV-positive HNSCC might be related with changes in sexual behavior $(5,9,10)$. HPV-positive OPSCC patients generally tend to be younger and sexually active males, consume less or no alcohol, and are non-smokers $(11,12)$. Most HPV-positive OPSCC present with early T classification, while often having cystic and multi-level nodal metastases (13). However, HPV-positive OPSCC showed better survival outcomes compared with HPV-negative tumors $(5,14,15)$.

The prevalence of HPV in HNSCC is quite diverse, depending on the region and country. In general, the incidence of HPVrelated OPSCC has increased over time, and most HPV-unrelated HNSCC decreased or remained stable $(2,16)$. According to a systematic review study performed in Europe, the positive rate of HPV in OPSCC ranges from 18-65\% (17). Another metaanalysis study reported a sharp increase in the proportion of HPV-positive OPSCC up to 72.2\% between 2005 and 2009 in North America and Europe (18).

However, the HPV positive rate and recent incidence trend in HNSCC have not been thoroughly investigated in South Korea. Thus, this study aimed to investigate the positive rate of HPV and its trend in HNSCC in South Korea and to evaluate the clinical differences between HPV-positive and HPV-negative HNSCC, especially for OPSCC.

\section{MATERIALS AND METHODS}

We retrospectively analyzed all patients with HNSCC in the oropharynx, oral cavity, larynx, hypopharynx, and sinonasal cavity treated in a tertiary university hospital in Seoul, South Korea, from January 2008 to July 2020. All patients were diagnosed with squamous cell carcinoma (SCC) pathologically. We excluded patients with nasopharyngeal cancer, salivary cancer, skin cancer, and unknown primary tumors. We also excluded those who had malignant tumors other than SCC, those who had incomplete medical records or were not followed up for at least six months, or those whose formalin-fixed paraffinembedded tissue blocks were not available (especially patients diagnosed before 2008 because the paraffin blocks were available from 2008 in our institute) from the study. After these exclusions, finally, 300 patients were included and analyzed in this study. This study was approved by the Institutional Review Board (IRB) (IRB No: 2020-07-046).

HPV status of primary tumors was determined using p16 immunohistochemistry (IHC) staining. IHC was performed on $4-\mu \mathrm{m}$ thick, formalin-fixed, paraffin-embedded tissue sections using the Ventana Benchmark XT automated staining system (Ventana Medical Systems, Tucson, AZ, USA) according to the manufacturer's instructions. Immunohistochemical staining for p16 was performed using the CINtec Histology Kit (clone E6H4, REF 805-4713, Ventana Medical Systems, Tucson, AZ, USA). P16 IHC results were considered positive when there was diffuse moderate or strong nuclear and cytoplasmic staining with grade 2 (moderate) or 3 (strong) intensities and more than $75 \%$ distribution in the tumor cells according to the American Joint Commission on Cancer (AJCC) 8th guidelines (19).

We reviewed the medical records and analyzed the demographic and clinicopathological characteristics, including smoking, alcohol consumption, extracapsular spread, TNM stage, treatment methods, recurrence, and survival. TNM staging was categorized according to the American Joint Commission on Cancer (AJCC) Staging Manual 8th edition (19).

SPSS 21.0 (IBM, Armonk, NY) was used for statistical analysis. The chi-square test and Fisher's exact test were used to compare sex, extracapsular spread, smoking, alcohol consumption, TNM staging, and treatment methods between patients with HPVpositive and -negative tumors. A $t$-test was used for age. Statistical significance was set at $P<0.05$. Overall survival (OS) and disease-free survival (DFS) curves were analyzed over 5 years using the Kaplan-Meier method.

\section{RESULTS}

Of 300 patients with HNSCC, the distribution of the primary site was the oropharynx in 77 patients $(25.7 \%)$, oral cavity in 65 (21.7\%), larynx in 106 (35.3\%), hypopharynx in 40 (13.3\%), and sinonasal cavity in $12(4 \%)$.

The demographics and clinicopathological characteristics of the patients are summarized in Table 1. Of the 300 patients, 246 were males and 54 were females. The proportion of females was higher in the oral cavity cancer site than in the other primary sites $(P<0.001)$. The mean age was $62.3 \pm 11.3$ years. The mean age was not significantly different between the five primary sites $(P=0.081)$. Thirty-nine percent of the patients were smokers, and $46 \%$ of patients consumed alcohol. The incidence of alcohol consumption was higher in hypopharyngeal cancer than in the four other primary site cancers $(P=0.026)$. The proportion of patients with advanced stage (stage III/IV) was higher in hypopharyngeal and sinonasal cancers $(P<0.001)$. In terms of treatment, the proportion of definitive radiation or concurrent chemoradiation therapy was higher in hypopharyngeal and sinonasal cancers $(P<0.001)$.

Of the 300 patients, the positive rate of p16 was $30.3 \%$ (91/300). The positive rate of p16 was 70.1, 13.9, 20.8, 15, and $0 \%$ in the oropharynx, oral cavity, larynx, hypopharynx, and sinonasal cavity, respectively. The HPV-positive rate was significantly higher in OPSCC than in the other primary sites $(P$ $<0.05$ ) (Table 1).

Comparisons of HPV-positive and HPV-negative tumors are shown in Table 2. In the oropharynx, the mean age of HPVpositive OPSCC was significantly lower than that of HPVnegative OPSCC (58.6 and 64.2 years in HPV-positive and negative OPSCC, respectively, $P=0.024$ ). The proportion of patients with advanced stage (stage III/IV) was significantly lower 
TABLE 1 | Demographics and characteristics of patients with head and neck squamous cell carcinoma.

\begin{tabular}{|c|c|c|c|c|c|c|}
\hline & $\begin{array}{l}\text { Oropharynx } \\
\qquad(n=77)\end{array}$ & $\begin{array}{l}\text { Oral cavity } \\
\qquad(n=65)\end{array}$ & $\begin{array}{c}\text { Larynx } \\
(n=106)\end{array}$ & $\begin{array}{l}\text { Hypopharynx } \\
(n=40)\end{array}$ & $\begin{array}{l}\text { Sinonasal cavity } \\
\qquad(n=12)\end{array}$ & $P$ value \\
\hline Age & $60.3 \pm 10.0$ & $60.0 \pm 14.5$ & $64.8 \pm 10.0$ & $64.8 \pm 9.6$ & $57.9 \pm 10.7$ & 0.081 \\
\hline Male & 65 (84.4\%) & 32 (49.2\%) & 101(95.3\%) & 37 (92.5\%) & $11(91.7 \%)$ & \\
\hline Female & $12(15.6 \%)$ & 33 (50.8\%) & $5(4.7 \%)$ & $3(7.5 \%)$ & $1(8.3 \%)$ & \\
\hline HPV & & & & & & $<0.001$ \\
\hline$(-)$ & 23 (29.9\%) & $56(86.2 \%)$ & 84 (79.2\%) & 34 (85.0\%) & $12(100 \%)$ & \\
\hline Smoking & & & & & & 0.813 \\
\hline Non-smoker & $47(61.0 \%)$ & $43(66.2 \%)$ & 60 (56.6\%) & 24 (60.0\%) & 7 (58.3\%) & \\
\hline Smoker & $30(39.0 \%)$ & $22(33.8 \%)$ & 46 (43.4\%) & $16(40.0 \%)$ & $5(41.7 \%)$ & \\
\hline Alcohol consumption & & & & & & 0.026 \\
\hline No & $40(51.9 \%)$ & 42 (64.6\%) & $53(50.0 \%)$ & $16(40.0 \%)$ & $10(83.3 \%)$ & \\
\hline$(-)$ & $20(64.5 \%)$ & $8(44.4 \%)$ & $6(85.7 \%)$ & $6(50.0 \%)$ & $0(0.0 \%)$ & \\
\hline T classification & & & & & & $<0.001$ \\
\hline T1 & 20 (26.0\%) & 29 (44.6\%) & 60 (56.6\%) & 10 (25.0\%) & $3(25.0 \%)$ & \\
\hline T2 & $38(49.4 \%)$ & $20(30.8 \%)$ & $15(14.2 \%)$ & $10(25.0 \%)$ & $2(16.7 \%)$ & \\
\hline T3 & $12(15.6 \%)$ & $11(16.9 \%)$ & $15(14.2 \%)$ & $8(20.0 \%)$ & $3(25.0 \%)$ & \\
\hline T4 & $7(9.1 \%)$ & $5(7.7 \%)$ & $16(15.0 \%)$ & $12(30.0 \%)$ & $4(33.3 \%)$ & \\
\hline $\mathrm{N}$ classification & & & & & & $<0.001$ \\
\hline NO & $24(31.2 \%)$ & $42(64.6 \%)$ & $81(76.4 \%)$ & $11(27.5 \%)$ & $6(50.0 \%)$ & \\
\hline N1 & $29(37.7 \%)$ & $9(13.8 \%)$ & $9(8.5 \%)$ & $11(27.5 \%)$ & $4(33.3 \%)$ & \\
\hline N2 & $17(22.1 \%)$ & $10(15.4 \%)$ & $14(13.2 \%)$ & $16(40.0 \%)$ & $2(16.7 \%)$ & \\
\hline N3 & 7 (9.1\%) & $4(6.2 \%)$ & 2 (1.9\%) & 2 (5.0\%) & $0(0 \%)$ & \\
\hline IV & $12(15.6 \%)$ & $18(27.7 \%)$ & 27 (25.5\%) & $29(72.5 \%)$ & $5(41.7 \%)$ & \\
\hline Treatment & & & & & & $<0.001$ \\
\hline Surgery & $11(14.3 \%)$ & 33 (50.8\%) & 38 (35.8\%) & 5 (12.5\%) & $3(25.0 \%)$ & \\
\hline Surgery + Postop. RT or CCRT & 55 (71.4\%) & $31(47.7 \%)$ & $50(47.2 \%)$ & $22(55.0 \%)$ & $5(41.7 \%)$ & \\
\hline Definitive RT or CCRT & $6(7.8 \%)$ & $0(0.0 \%)$ & $8(7.5 \%)$ & $11(27.5 \%)$ & $4(33.3 \%)$ & \\
\hline Others & 5 (6.5\%) & $1(1.5 \%)$ & 10 (9.4\%) & 2 (5.0\%) & $0(0 \%)$ & \\
\hline
\end{tabular}

HPV, human papilloma virus; RT, radiation therapy; CCRT, concurrent chemoradiation therapy.

in HPV-positive OPSCC than in HPV-negative tumors $(P<$ 0.001). Sex, smoking, alcohol consumption, T classification, and $\mathrm{N}$ classification were not different between HPV-positive and HPV-negative OPSCC. In the other primary sites, including the oral cavity, larynx, hypopharynx, and sinonasal cavity, all parameters, such as age, sex, smoking, alcohol consumption, TNM stage, and treatment methods did not differ between the HPV-positive and-negative tumors.

When comparing the four sub-sites of the oropharynx, the positive rate of HPV was $78.4 \%(40 / 51)$ in the tonsil, $61.9 \%$ $(13 / 21)$ in the base of the tongue, $0 \%(0 / 1)$ in the soft palate, and $25 \%(1 / 4)$ in the posterior wall (Table 3$)$.
HPV positivity in OPSCC tended to increase over time from 2008 to 2020 (Figure 1). The positive rate of HPV infection in OPSCC was 33.3\% in 2008-2009 and increased to $83.3 \%$ in 2020 . The incidence of HPV-positive and HPV-negative OPSCC was reversed between 2009 and 2010 (Figure 1). In the other primary sites, the positive rate of HPV did not change significantly over the years (Figure 2).

The median follow-up time after treatment was 34 months (range, 6-124 months). The Kaplan-Meier curve of DFS of HPV-positive OPSCC was significantly higher than that of HPV-negative OPSCC (Figure 3). The OS curves were 
TABLE 2 | Comparisons of head and neck squamous cell carcinoma according to HPV status.

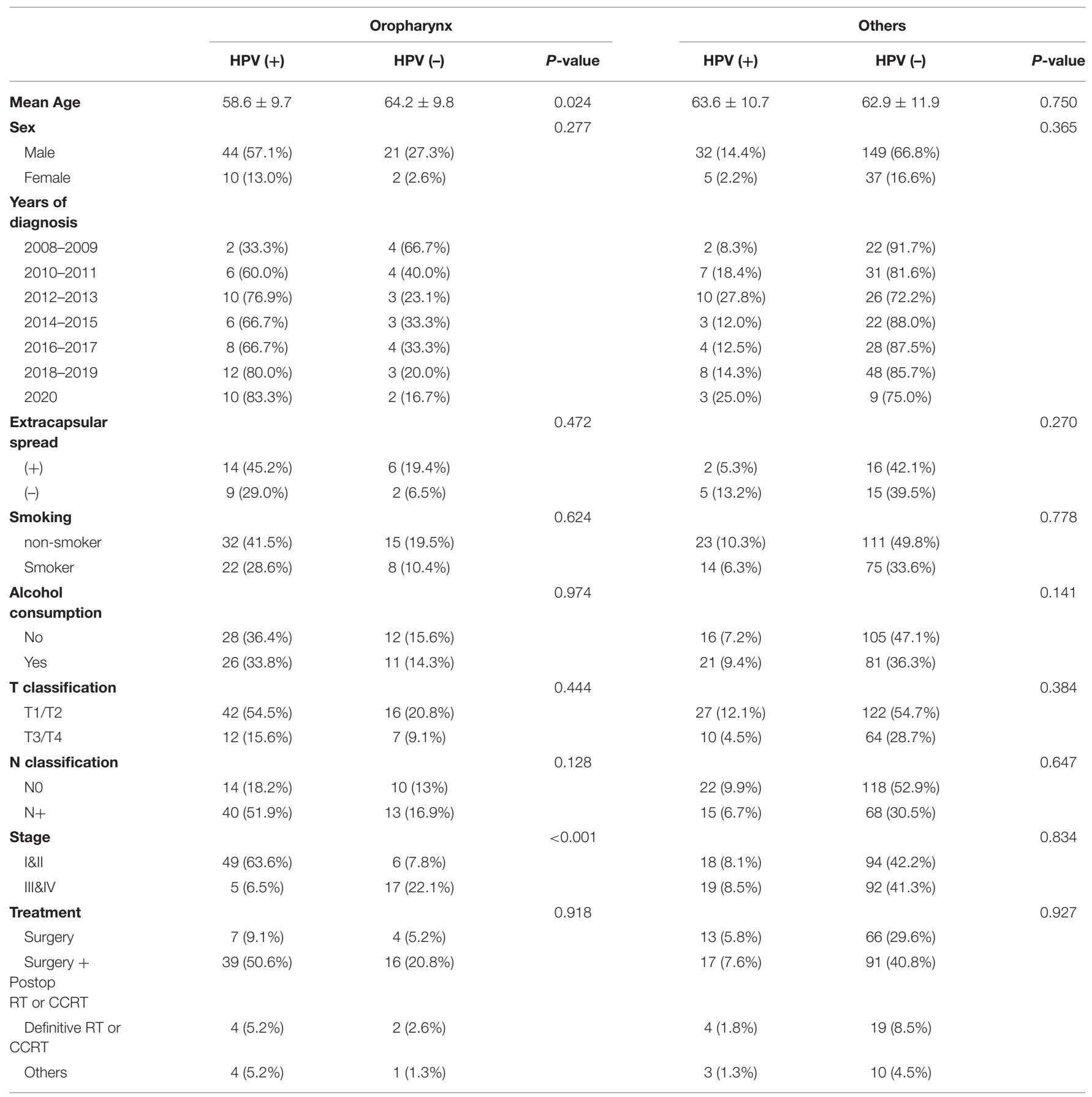

HPV, human papilloma virus; $R T$, radiation therapy; CCRT, concurrent chemoradiation therapy.

not statistically different between HPV-positive and HPVnegative OPSCC, although the OS of HPV-positive OPSCC tended to be higher than that of negative tumors. The DFS and OS curves did not differ between HPV-positive and HPV-negative tumors in patients with oral cancer, laryngeal cancer, and hypopharyngeal cancer. According to the stage, the DFS of stage I/II disease was significantly higher than that of stage III/IV disease in OPSCC and cancer of other primary sites.

\section{DISCUSSION}

The prevalence of HPV in OPSCC is rising worldwide, starting from developed Western countries, and it differs significantly across different countries and cultures $(16,20)$. The well-known high-burden regions for HPV in OPSCC are North America and northern Europe, including the United States [81.6\% (21), 74\% (22), 67\% (23), 66\% (24), 65\% (25), and 58\% (26)], Canada (57\%) (27), Sweden [68\% (28), 70\% (29), and 85\% (30)], Denmark 
TABLE 3 | Comparisons of oropharyngeal squamous cell carcinoma according to the sub-site.

Tonsil $(n=51) \quad$ BOT $(n=21)$

Soft palate $(n=1)$

$\operatorname{PPW}(n=4)$

$\operatorname{HPV}(+)(n=40) \quad \operatorname{HPV}(-)(n=11) \quad P$-value $\operatorname{HPV}(+)(n=13) \quad \operatorname{HPV}(-)(n=8) \quad P$-value $\quad \operatorname{HPV}(+)(n=0) \quad \operatorname{HPV}(-)(n=1) \quad P$-value $\quad \operatorname{HPV}(+)(n=1) \quad \operatorname{HPV}(-)(n=3) \quad P$-value

\begin{tabular}{|c|c|c|c|c|c|c|c|c|c|c|c|c|}
\hline Mean age & $57.9 \pm 10.2$ & $64.4 \pm 10.6$ & 0.073 & $60.8 \pm 8.3$ & $62.5 \pm 11.6$ & 0.694 & - & 65.0 & - & 55.0 & $67.7 \pm 2.5$ & 0.049 \\
\hline Gender & & & 0.135 & & & 0.920 & & & - & & & - \\
\hline Male & 33 (64.7\%) & $11(21.6 \%)$ & & $10(47.6 \%)$ & $6(28.6 \%)$ & & - & $1(100 \%)$ & & $1(25.0 \%)$ & $3(75.0 \%)$ & \\
\hline Female & 7 (13.7\%) & $0(0 \%)$ & & $3(14.3 \%)$ & 2 (9.5\%) & & - & - & & $0(0.0 \%)$ & $0(0.0 \%)$ & \\
\hline Smoking & & & 0.290 & & & 0.477 & & & - & & & 0.248 \\
\hline Non-smoker & 22 (43.1\%) & $8(15.7 \%)$ & & $10(47.6 \%)$ & $5(23.8 \%)$ & & - & - & & $0(0.0 \%)$ & $2(50.0 \%)$ & \\
\hline Smoker & 18 (35.3\%) & 3 (5.9\%) & & 3 (14.3\%) & $3(14.3 \%)$ & & - & $1(100 \%)$ & & 1 (25.0\%) & 1 (25.0\%) & \\
\hline $\begin{array}{l}\text { Alcohol } \\
\text { consumption }\end{array}$ & & & 0.861 & & & 0.965 & & & - & & & 0.046 \\
\hline No & 23 (45.1\%) & $6(11.8 \%)$ & & 5 (23.8\%) & $3(14.3 \%)$ & & - & - & & $0(0.0 \%)$ & $3(75.0 \%)$ & \\
\hline Yes & 17 (33.3\%) & 5 (10.0\%) & & $8(38.1 \%)$ & 5 (23.8\%) & & - & $1(100 \%)$ & & 1 (25.0\%) & $0(0.0 \%)$ & \\
\hline $\mathrm{T}$ classification & & & 0.470 & & & 0.776 & & & - & & & 0.505 \\
\hline $\mathrm{T} 1 / \mathrm{T} 2$ & $33(64.7 \%)$ & $8(15.7 \%)$ & & $9(42.9 \%)$ & $6(28.6 \%)$ & & - & $1(100 \%)$ & & $0(0 \%)$ & $1(25 \%)$ & \\
\hline $\mathrm{T} 3 / \mathrm{T} 4$ & 7 (13.7\%) & $3(5.9 \%)$ & & $4(19 \%)$ & $2(9.5 \%)$ & & - & - & & $1(25 \%)$ & $2(50 \%)$ & \\
\hline $\mathrm{N}$ classification & & & 0.256 & & & 0.920 & & & - & & & 0.248 \\
\hline NO & $11(21.6 \%)$ & 5 (9.8\%) & & $3(14.3 \%)$ & $2(9.5 \%)$ & & - & $1(100 \%)$ & & $0(0 \%)$ & $2(50 \%)$ & \\
\hline $\mathrm{N}+$ & 29 (56.9\%) & $6(11.8 \%)$ & & $10(47.6 \%)$ & $6(28.6 \%)$ & & - & - & & $1(25 \%)$ & $1(25 \%)$ & \\
\hline Stage & & & $<0.001$ & & & 0.006 & & & & & & - \\
\hline$|\&| \mid$ & 38 (74.5\%) & 3 (5.9\%) & & $11(52.4 \%)$ & 2 (9.5\%) & & - & $1(100 \%)$ & & - & - & \\
\hline III\&IV & 2 (3.9\%) & $8(15.7 \%)$ & & 2 (9.5\%) & $6(28.6 \%)$ & & - & - & & $1(25 \%)$ & $3(75 \%)$ & \\
\hline Treatment & & & 0.596 & & & 0.072 & & & - & & & 0.135 \\
\hline Surgery & 5 (9.8\%) & $1(2 \%)$ & & 2 (9.5\%) & $3(14.3 \%)$ & & - & - & & - & - & \\
\hline $\begin{array}{l}\text { Surgery + } \\
\text { Postop } \\
\text { RT or CCRT }\end{array}$ & 32 (62.7\%) & 10 (19.6\%) & & 7 (33.3\%) & $3(14.3 \%)$ & & - & $1(100 \%)$ & & - & $2(50 \%)$ & \\
\hline $\begin{array}{l}\text { Definitive RT or } \\
\text { CCRT }\end{array}$ & $3(5.9 \%)$ & $0(0 \%)$ & & $0(0 \%)$ & $2(9.5 \%)$ & & - & - & & $1(25 \%)$ & - & \\
\hline Others & - & - & & $4(19.0 \%)$ & - & & - & - & & - & $1(25 \%)$ & \\
\hline
\end{tabular}

BOT, base of tongue; PPW, posterior pharyngeal wall; HPV, human papilloma virus; RT, radiation therapy; CCRT, concurrent chemoradiation therapy. 


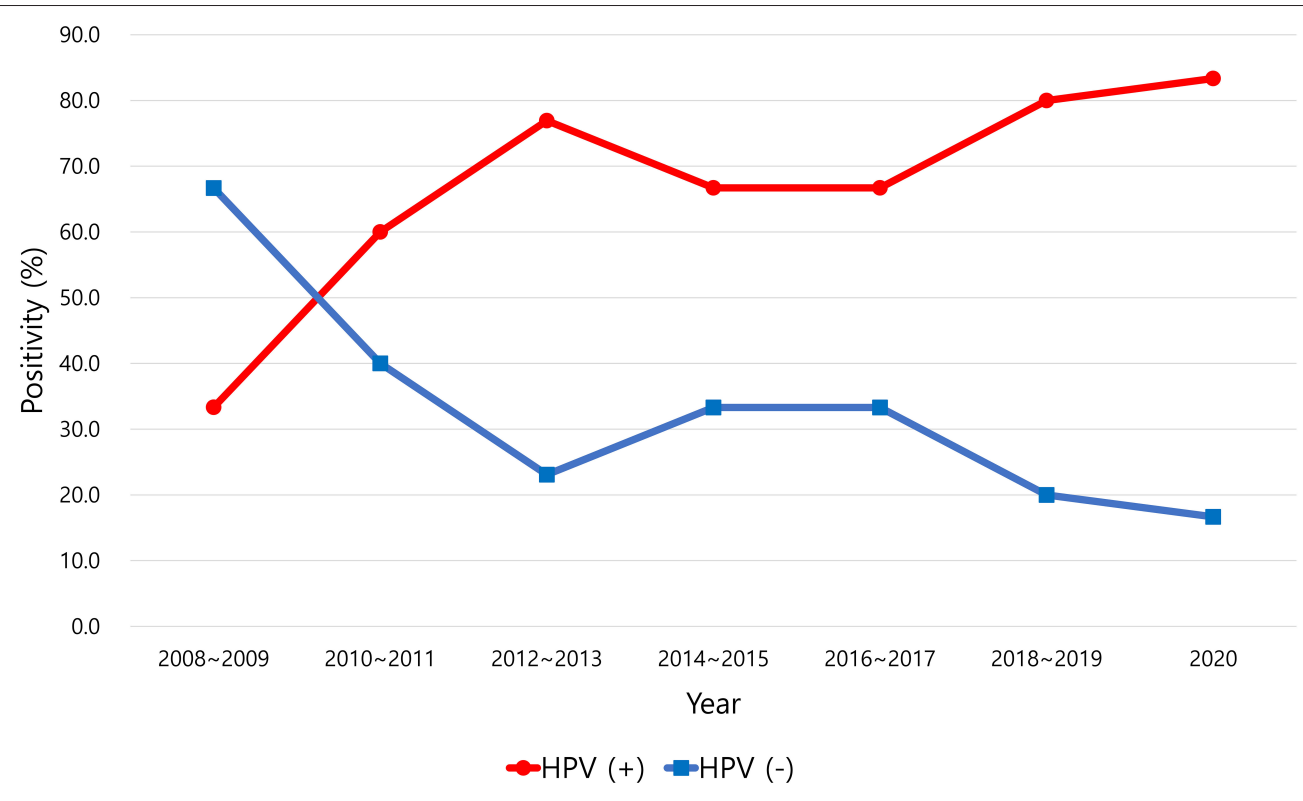

FIGURE 1 | Positive rate of human papillomavirus (HPV) in oropharyngeal squamous cell carcinoma.

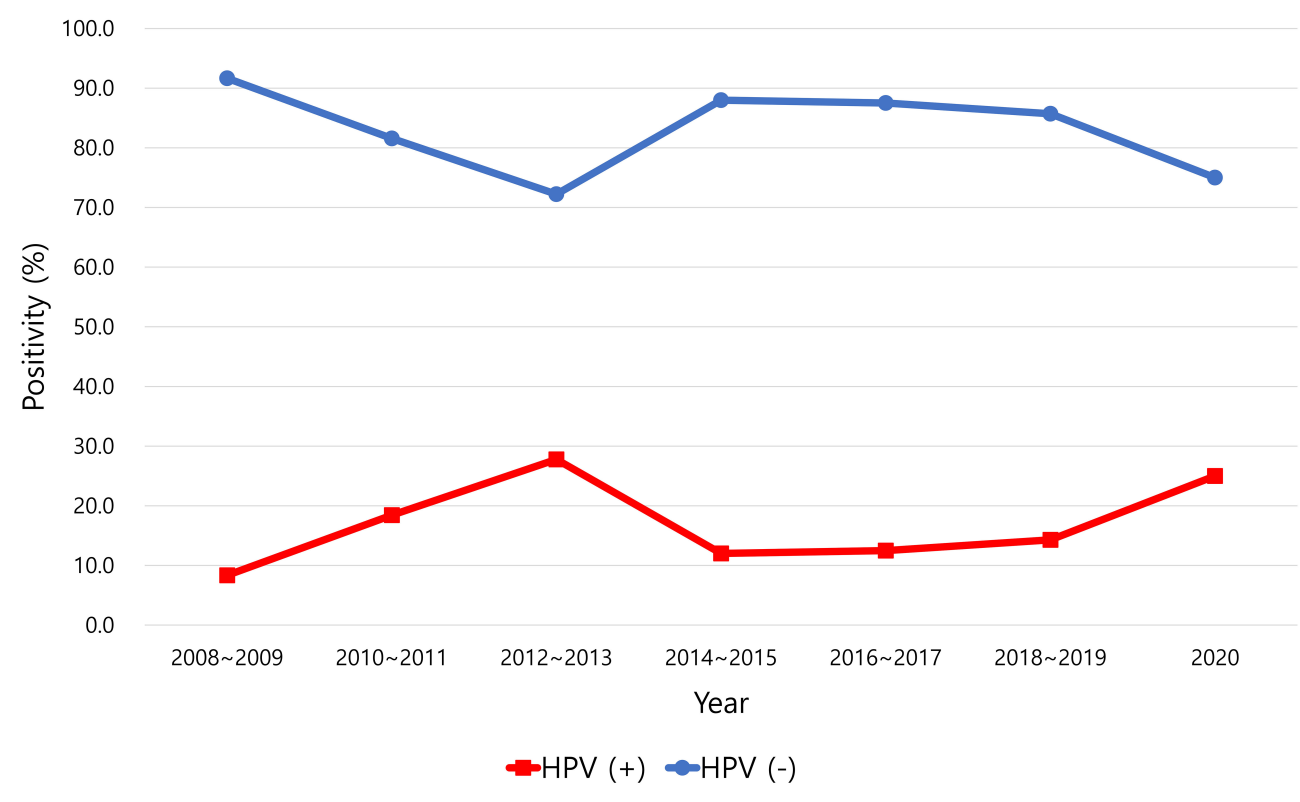

FIGURE 2 | Positive rate of human papillomavirus (HPV) in squamous cell carcinoma of the oral cavity, larynx, hypopharynx, and sinonasal cavity.

(52\%) (31), France [46.5\% (32) and 50.4\% (33)], and Norway [52\% (34) and 77\% (35)].

Southeast Europe is known to be a relatively low-burden region in Western countries. However, a study conducted in Greece showed an increased rate of HPV-positive OPSCC in 2000-2007 (50\%) compared to that in 1992-1998 (17\%) (36). A recent increased incidence of HPV-positive OPSCC was also reported in Spain from $8.2 \%$ in $2007-2011$ to $21.5 \%$ in $2012-$ 2016 (37). Another study conducted in Italy also showed an increase in HPV-positive OPSCC from 16.7\% in early 2000-2006 to $46.2 \%$ in $2013-2018$ (38). In Australia, the positivity rate of $\mathrm{HPV}$ in OPSCC increased from $20.2 \%$ in $1987-1995$ to $63.5 \%$ in 2006-2010 (10). In Brazil, a study using a birth cohort revealed an increase in HPV-related oropharyngeal/oral cancer in young males and females (12).

Asia has a relatively lower prevalence of HPV-positive OPSCC, although the incidence has been increasing in recent years. One study revealed an increasing incidence of HPV in 


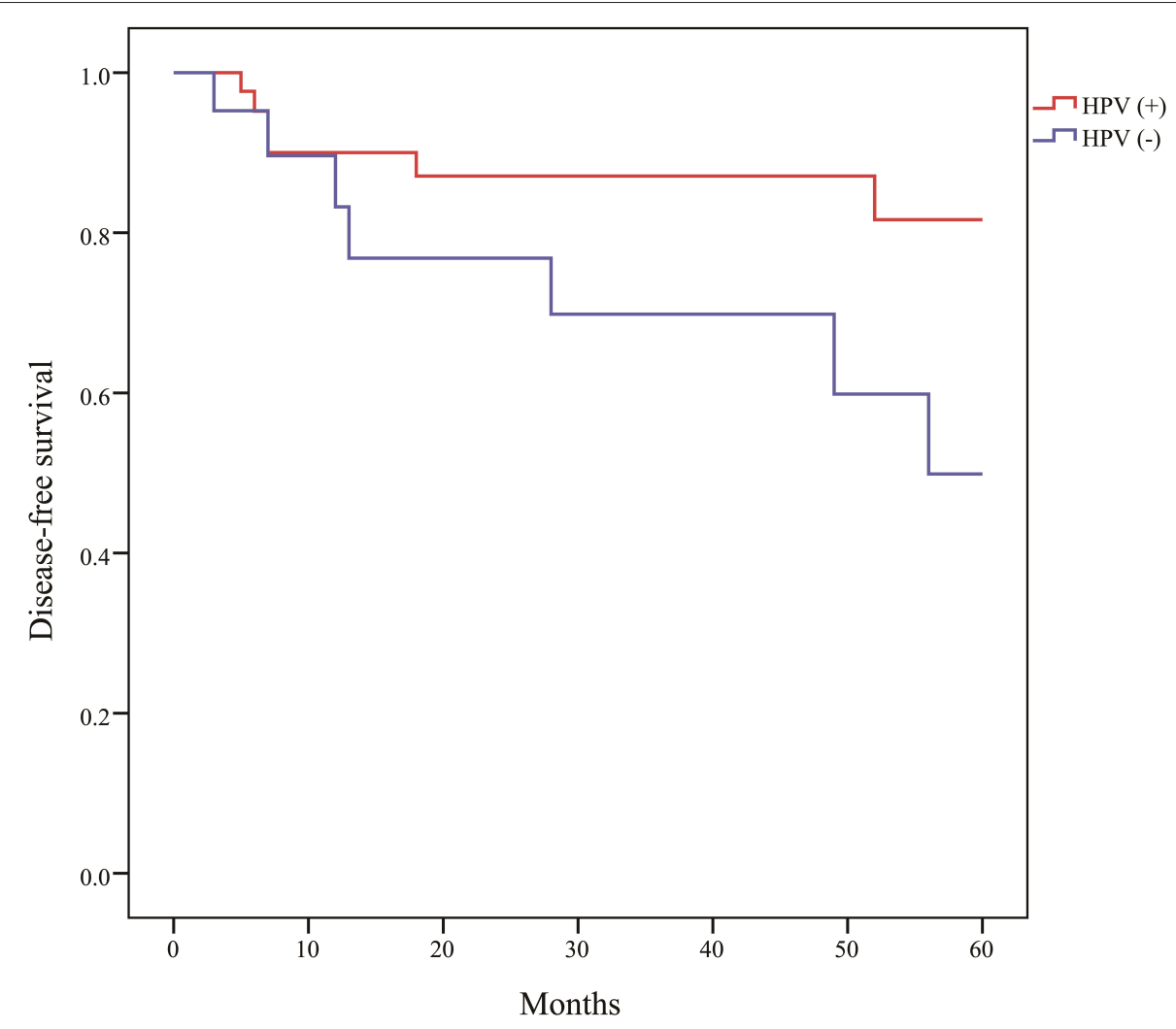

FIGURE 3 | Disease-free survival of oropharyngeal squamous cell carcinoma according to human papillomavirus (HPV) status $(P=0.028)$.

Thailand, with an annual increase of $2 \%$ from $16 \%$ in 2012 to $26 \%$ in 2017 (39). The HPV-positive rate of OPSCC in Asia was reported to be $28 \%$ in Thailand (40), $12.6 \%$ in Taiwan (41), $22.8 \%$ in India (42), 39\% in southern China (43), 45\% in Singapore (44), and $44 \%$ in Japan (45).

In this study, the HPV-positive rate of OPSCC was 70.1\%, and the positive rate showed a dramatic increase from $33.3 \%$ in 2008 2009 to $80 \%$ in 2020 . HPV-positive OPSCC outnumbered HPVnegative OPSCC in 2009-2010. The recent positive rate of HPV in OPSCC in South Korea seems to be similar to that in Western countries. Chaturvedi et al. revealed a rising incidence of HPVpositive OPSCC in the United States, from $16.3 \%$ in the 1980 s to $71.7 \%$ in the 2000 s (9). In their study, HPV-positive OPSCC outnumbered HPV-negative OPSCC in the mid-1990s (9). The time gap when HPV-positive OPSCC overtakes HPV-negative OPSCC is approximately 15 years between the United States and South Korea.

In previous studies performed in South Korea for patients in 1994-2010, the positive rate of HPV in OPSCC ranged from 23.4 to $49.5 \%$ (46-50). In a recent study conducted in South Korea, the positive rate of HPV was $73 \%$ by $\mathrm{p} 16$ IHC in patients with OPSCC between 2011 and 2019, similar to that shown in this study (51). Recently, Jung et al. performed a study using the Korea Central Cancer Registry to evaluate the recent incidence trend of head and neck cancer (52). They reported increased HPV-related oropharyngeal cancer and a slight decrease in HPV-unrelated head and neck cancer. Interestingly, the incidence of tonsillar cancer increased continuously from 1999 to 2011 but seemed to stabilize thereafter until 2020 (52). However, they did not evaluate the HPV status in their study. Therefore, they could not confirm that the increase in tonsillar cancer was associated with increased HPV-positive cancer. The current study showed that the positive rate of HPV in OPSCC tended to increase over time from 2008 to 2020, similar to the increase in oropharyngeal cancer in Jung's study. Therefore, this study might suggest that the increased incidence of OPSCC in South Korea is associated with an increase in HPV-positive tumors.

Generally, the positive rate of HPV in the other primary sites is low compared to that in the oropharynx. In this study, HPV positivity was $13.9,20.8$, and $15 \%$ in the oral cavity, larynx, and hypopharynx, respectively. The incidence of HPV positivity in oral cancer was reported to be $26 \%$ in Croatia (53), 31\% in India (42), $6.9 \%$ in the United States (54), 10.5\% in France (32), 3.4\% in Brazil (55), and $0.6 \%$ in South Korea (51). The HPV-positive rate of laryngeal cancer was also diverse across countries. It was $4 \%$ in Mexico (56), 7.2\% in Thailand (39), 9\% in Italy (57), $10.6 \%$ in Austria (58), $11.6 \%$ in South Korea (51), 20\% in Turkey (59), 25.8\% in China (43), and 60\% in Spain (60). The HPV positivity of hypopharyngeal cancer varied from 5\% (61) and 21.6\% (62) in the United States, 4.1\% in Austria (58), 5\% in Spain (60), 16.5\% in Sweden (63), and 10\% in South Korea (64). An international multicenter study performed in 2016, including 29 
countries, reported a 3.9\% HPV positivity rate in hypopharyngeal cancer (65).

In sinonasal cancer, the rate of HPV positivity was $20 \%$ in India (66), 23\% (67) and 53\% (68) in the United States, $15.7 \%$ in Eastern China (69), and 28\% in South Korea (51). The current study revealed $0 \%(0 / 12)$ of HPV positivity in sinonasal cancer, which is significantly different from that found in other studies. This might be associated with the small sample size of the 12 patients in this study. Further studies with a larger sample size are necessary to clarify the positive rate of HPV in sinonasal cancer.

Currently, there is no standard method to examine the HPV status of clinical cancer samples. The targets for HPV testing might include p16 protein, HPV DNA or mRNA, viral oncoproteins, and HPV-specific serum antibodies (6). The reliable and effective tool is determined by accuracy, feasibility, and cost-effectiveness. The method of directly detecting viral DNA using polymerase chain reaction (PCR) has high sensitivity and can identify high-risk HPV (70). In situ hybridization (ISH) enables direct identification of HPV in topographical relationship to tumor cells (70). However, the most popular and cost-effective method for the detection of HPV is p16 IHC. The overexpression of p16 is a surrogate indicator of HPV infection (70). The eighth edition of the AJCC cancer staging guidelines recommends p16 IHC as a standard marker for HPV infection in OPSCC (19). However, p16 IHC might not be sufficient as a single marker for detection of HPV infection because approximately 10-15\% of $\mathrm{p} 16$ positive tumors do not reveal the presence of HPV in ISH or PCR testing for the virus $(71,72)$. This study evaluated HPV status using only p16 IHC, which is more widely used clinically than HPV PCR or ISH. Therefore, caution should be exercised when interpreting the results of this study.

It is known that the survival rate of HPV-positive OPSCC is better than that of HPV-negative tumors $(5,14,15,35)$. This study confirmed that the DFS of HPV-positive OPSCC is significantly better than that of HPV-negative tumors $(P=$ 0.028), similar to that reported in previous studies.

This study had some limitations. First, it was a retrospective study conducted in a single institute, and this study included a relatively small sample size. Therefore, selection bias is inevitable. The results of this study may not represent the actual HPV status of HNSCC in South Korea. Second, we performed only p16 IHC staining without HPV genotyping to analyze the HPV

\section{REFERENCES}

1. Auperin A. Epidemiology of head and neck cancers: an update. Curr Opin Oncol. (2020) 32:178-86. doi: 10.1097/CCO.0000000000000629

2. Rettig EM, D'Souza G. Epidemiology of head and neck cancer. Surg Oncol Clin N Am. (2015) 24:379-96. doi: 10.1016/j.soc.2015.03.001

3. Gillison ML, Koch WM, Capone RB, Spafford M, Westra WH, Wu L. Evidence for a causal association between human papillomavirus and a subset of head and neck cancers. J Natl Cancer Inst. (2000) 92:70920. doi: 10.1093/jnci/92.9.709

4. IARC. IARC monographs on the evaluation of carcinogenic risks to humans. In: Human Papillomavirus, World Health Organization. (2007). vol. 90.

5. Du E, Mazul AL, Farquhar D, Brennan P, Anantharaman D, Abedi-Ardekani B. Long-term survival in head and neck cancer: impact of site, stage, status. Therefore, HPV status might not be determined precisely, although the AJCC guidelines recommend p16 IHC as the standard method. A further multicenter study with a larger study sample and additional HPV genotyping is necessary to overcome the limitations of this study.

Despite these limitations, it is noteworthy that this study is the first to show a significant increase in HPV positivity in OPSCC in South Korea during the past 12 years, close to the positive rate found in Western countries.

\section{CONCLUSIONS}

The positive rate of HPV was significantly higher in OPSCC than in other head and neck primary site cancers in South Korea. The HPV positivity of OPSCC has been increasing abruptly during the past 12 years, and it is becoming similar to the positive rate found in North America and Europe. The DFS of HPV-positive OPSCC was significantly better than that of HPV-negative tumors.

\section{DATA AVAILABILITY STATEMENT}

The original contributions presented in the study are included in the article/supplementary material, further inquiries can be directed to the corresponding author/s.

\section{ETHICS STATEMENT}

The studies involving human participants were reviewed and approved by the Institutional Review Board (IRB) of Hanyang University Hospital. The patients/participants provided their written informed consent to participate in this study.

\section{AUTHOR CONTRIBUTIONS}

HJ: initial draft, data acquisition, analysis, critical revision of manuscript, and final approval. YJ, CS, JM, HP: data acquisition, analysis, critical revision of manuscript, and final approval. KT: conception and design of the work, data analysis and interpretation, critical revision of manuscript, and final approval. All authors contributed to the article and approved the submitted version. smoking, and human papillomavirus status. Laryngoscope. (2019) 129:250613. doi: 10.1002/lary.27807

6. Rahimi S. HPV-related squamous cell carcinoma of oropharynx: a review. $J$ Clin Pathol. (2020) 73:624-9. doi: 10.1136/jclinpath-2020-206686

7. Syrjanen K, Syrjanen S, Lamberg M, Pyrhonen S, Nuutinen J. Morphological and immunohistochemical evidence suggesting human papillomavirus (HPV) involvement in oral squamous cell carcinogenesis. Int J Oral Surg. (1983) 12:418-24. doi: 10.1016/S0300-9785(83)80033-7

8. Menezes FDS, Fernandes GA, Antunes JLF, Villa LL, Toporcov TN. Global incidence trends in head and neck cancer for HPV-related and -unrelated subsites: A systematic review of population-based studies. Oral Oncol. (2021) 115:105177. doi: 10.1016/j.oraloncology.2020.105177

9. Chaturvedi AK, Engels EA, Pfeiffer RM, Hernandez BY, Xiao W, Kim E. Human papillomavirus and rising oropharyngeal 
cancer incidence in the United States. J Clin Oncol. (2011) 29:4294-301. doi: 10.1200/JCO.2011.36.4596

10. Hong A, Lee CS, Jones D, Veillard AS, Zhang M, Zhang X. Rising prevalence of human papillomavirus-related oropharyngeal cancer in Australia over the last 2 decades. Head Neck. (2016) 38:743-50. doi: 10.1002/hed.23942

11. Ang KK, Harris J, Wheeler R, Weber R, Rosenthal DI, Nguyen-Tan PF. Human papillomavirus and survival of patients with oropharyngeal cancer. N Engl J Med. (2010) 363:24-35. doi: 10.1056/NEJMoa0912217

12. Menezes FDS, Latorre M, Conceicao GMS, Curado MP, Antunes JLF, Toporcov TN. The emerging risk of oropharyngeal and oral cavity cancer in HPV-related subsites in young people in Brazil. PLoS ONE. (2020) 15:e0232871. doi: 10.1371/journal.pone.0232871

13. Goldenberg D, Begum S, Westra WH, Khan Z, Sciubba J, Pai SI. Cystic lymph node metastasis in patients with head and neck cancer: An HPV-associated phenomenon. Head Neck. (2008) 30:898-903. doi: 10.1002/hed.20796

14. Machczynski P, Majchrzak E, Niewinski P, Marchlewska J, Golusinski W, A. review of the 8th edition of the AJCC staging system for oropharyngeal cancer according to HPV status. Eur Arch Otorhinolaryngol. (2020) 277:240712. doi: $10.1007 / \mathrm{s} 00405-020-05979-9$

15. Gooi Z, Chan JY, Fakhry C. The epidemiology of the human papillomavirus related to oropharyngeal head and neck cancer. Laryngoscope. (2016) 126:894900. doi: 10.1002/lary.25767

16. de Martel C, Plummer M, Vignat J, Franceschi S. Worldwide burden of cancer attributable to HPV by site, country and HPV type. Int J Cancer. (2017) 141:664-70. doi: 10.1002/ijc.30716

17. Stjernstrom KD, Jensen JS, Jakobsen KK, Gronhoj C, von Buchwald C. Current status of human papillomavirus positivity in oropharyngeal squamous cell carcinoma in Europe: a systematic review. Acta Otolaryngol. (2019) 139:1112-6. doi: 10.1080/00016489.2019.1669820

18. Mehanna H, Beech T, Nicholson T, El-Hariry I, McConkey C, Paleri V, et al. Prevalence of human papillomavirus in oropharyngeal and nonoropharyngeal head and neck cancer-systematic review and meta-analysis of trends by time and region. Head Neck. (2013) 35:747-55. doi: 10.1002/hed. 22015

19. Amin MB, Edge S, Greene F, Byrd DR, Brookland RK, Washington MK, et al. AJCC Cancer Staging Manual. 8th edn. New York, NY: Springer (2017).

20. Chaturvedi AK, Anderson WF, Lortet-Tieulent J, Curado MP, Ferlay J, Franceschi S. Worldwide trends in incidence rates for oral cavity and oropharyngeal cancers. J Clin Oncol. (2013) 31:4550-9. doi: 10.1200/JCO.2013.50.3870

21. Ju X, Canfell K, Smith M, Sethi S, Garvey G, Hedges J, et al. High-risk human papillomavirus-related oropharyngeal squamous cell carcinoma among nonindigenous and indigenous populations: a systematic review. Otolaryngol Head Neck Surg. (2021) 165:23-32. doi: 10.1177/0194599820975042

22. Mahal BA, Catalano PJ, Haddad RI, Hanna GJ, Kass JI, Schoenfeld JD. Incidence and demographic burden of HPV-associated oropharyngeal head and neck cancers in the United States. Cancer Epidemiol Biomarkers Prev. (2019) 28:1660-7. doi: 10.1158/1055-9965.EPI-19-0038

23. Jordan RC, Lingen MW, Perez-Ordonez B, He X, Pickard R, Koluder M. Validation of methods for oropharyngeal cancer HPV status determination in US cooperative group trials. Am J Surg Pathol. (2012) 36:94554. doi: 10.1097/PAS.0b013e318253a2d1

24. Senkomago V, Henley SJ, Thomas CC, Mix JM, Markowitz LE, Saraiya M. Human Papillomavirus-Attributable Cancers United States, 2012-2016. MMWR Morb Mortal Wkly Rep. (2019) 68:724-8. doi: 10.15585/mmwr.mm6833a3

25. Goodman MT, Saraiya M, Thompson TD, Steinau M, Hernandez BY, Lynch CF. Human papillomavirus genotype and oropharynx cancer survival in the United States of America. Eur J Cancer. (2015) 51:275967. doi: 10.1016/j.ejca.2015.09.005

26. Chaturvedi AK, D'Souza G, Gillison ML, Katki HA. Burden of HPV-positive oropharynx cancers among ever and never smokers in the US population. Oral Oncol. (2016) 60:61-7. doi: 10.1016/j.oraloncology.2016.06.006

27. Nichols AC, Palma DA, Dhaliwal SS, Tan S, Theuer J, Chow W. The epidemic of human papillomavirus and oropharyngeal cancer in a Canadian population. Curr Oncol. (2013) 20:212-9. doi: 10.3747/co.20.1375

28. Hammarstedt L, Lindquist D, Dahlstrand H, Romanitan M, Dahlgren LO, Joneberg J. Human papillomavirus as a risk factor for the increase in incidence of tonsillar cancer. Int J Cancer. (2006) 119:2620-3. doi: 10.1002/ijc. 22177

29. Haeggblom L, Attoff T, Yu J, Holzhauser S, Vlastos A, Mirzae L Changes in incidence and prevalence of human papillomavirus in tonsillar and base of tongue cancer during 2000-2016 in the Stockholm region and Sweden. Head Neck. (2019) 41:1583-90. doi: 10.1002/hed. 25585

30. Nasman A, Attner P, Hammarstedt L, Du J, Eriksson M, Giraud G. Incidence of human papillomavirus (HPV) positive tonsillar carcinoma in Stockholm, Sweden: an epidemic of viral-induced carcinoma? Int J Cancer. (2009) 125:362-6. doi: 10.1002/ijc.24339

31. Lassen P, Primdahl H, Johansen J, Kristensen CA, Andersen E, Andersen LJ. Impact of HPV-associated p16-expression on radiotherapy outcome in advanced oropharynx and non-oropharynx cancer. Radiother Oncol. (2014) 113:310-6. doi: 10.1016/j.radonc.2014.11.032

32. St Guily JL, Jacquard AC, Pretet JL, Haesebaert J, Beby-Defaux A, Clavel C. Human papillomavirus genotype distribution in oropharynx and oral cavity cancer in France-The EDiTH VI study. J Clin Virol. (2011) 51:1004. doi: 10.1016/j.jcv.2011.03.003

33. Melkane AE, Auperin A, Saulnier P, Lacroix L, Vielh P, Casiraghi O. Human papillomavirus prevalence and prognostic implication in oropharyngeal squamous cell carcinomas. Head Neck. (2014) 36:25765. doi: 10.1002/hed.23302

34. Hannisdal K, Schjølberg A, De Angelis PM, Boysen M, Clausen OP. Human papillomavirus (HPV)-positive tonsillar carcinomas are frequent and have a favourable prognosis in males in Norway. Acta Otolaryngol. (2010) 130:2939. doi: 10.3109/00016480903071377

35. Fossum GH, Lie AK, Jebsen P, Sandlie LE, Mork J. Human papillomavirus in oropharyngeal squamous cell carcinoma in South-Eastern Norway: prevalence, genotype, and survival. Eur Arch Otorhinolaryngol. (2017) 274:4003-10. doi: 10.1007/s00405-017-4748-8

36. Romanitan M, Nasman A, Ramqvist T, Dahlstrand H, Polykretis L, Vogiatzis P. Human papillomavirus frequency in oral and oropharyngeal cancer in Greece. Anticancer Res. (2008) 28:2077-80. Available online at: https://ar. iiarjournals.org/content/28/4B/2077

37. Mena M, Frias-Gomez J, Taberna M, Quiros B, Marquez S, Clavero O. Epidemiology of human papillomavirus-related oropharyngeal cancer in a classically low-burden region of southern Europe. Sci Rep. (2020) 10:13219. doi: 10.1038/s41598-020-70118-7

38. Del Mistro A, Frayle H, Menegaldo A, Favaretto N, Gori S, Nicolai P. Age-independent increasing prevalence of Human Papillomavirusdriven oropharyngeal carcinomas in North-East Italy. Sci Rep. (2020) 10:9320. doi: 10.1038/s41598-020-66323-z

39. Arsa L, Siripoon T, Trachu N, Foyhirun S, Pangpunyakulchai D, Sanpapant S. Discrepancy in p16 expression in patients with HPV-associated head and neck squamous cell carcinoma in Thailand: clinical characteristics and survival outcomes. BMC Cancer. (2021) 21:504. doi: 10.1186/s12885-021-08213-9

40. Argirion I, Zarins KR, McHugh J, Cantley RL, Teeramatwanich W, Laohasiriwong S, et al. Increasing prevalence of HPV in oropharyngeal carcinoma suggests adaptation of p16 screening in Southeast Asia. J Clin Virol. (2020) 132:104637. doi: 10.1016/j.jcv.2020.104637

41. Chien CY, Su CY, Fang FM, Huang HY, Chuang HC, Chen CM. Lower prevalence but favorable survival for human papillomavirus-related squamous cell carcinoma of tonsil in Taiwan. Oral Oncol. (2008) 44:1749. doi: 10.1016/j.oraloncology.2007.01.018

42. Nandi S, Mandal A, Chhebbi M. The prevalence and clinicopathological correlation of human papillomavirus in head and neck squamous cell carcinoma in India: a systematic review article. Cancer Treat Res Commun. (2021) 26:100301. doi: 10.1016/j.ctarc.2020.100301

43. Ni G, Huang K, Luan Y, Cao Z, Chen S, Ma B. Human papillomavirus infection among head and neck squamous cell carcinomas in southern China. PLoS ONE. (2019) 14:e0221045. doi: 10.1371/journal.pone.0221045

44. Tan LS, Fredrik P, Ker L, Yu FG, Wang Y, Goh BC. High-risk HPV genotypes and P16INK4a expression in a cohort of head and neck squamous cell carcinoma patients in Singapore. Oncotarget. (2016) 7:867309. doi: 10.18632 /oncotarget.13502

45. Sano D, Yabuki K, Arai Y, Tanabe T, Chiba Y, Nishimura G. The applicability of new TNM classification for humanpapilloma virus-related 
oropharyngeal cancer in the 8th edition of the AJCC/UICC TNM staging system in Japan: a single-centre study. Auris Nasus Larynx. (2018) 45:55865. doi: 10.1016/j.anl.2017.07.010

46. Kwon MJ, Kim DH, Park HR, Shin HS, Kwon JH, Lee DJ. Frequent hepatocyte growth factor overexpression and low frequency of c-Met gene amplification in human papillomavirus-negative tonsillar squamous cell carcinoma and their prognostic significances. Hum Pathol. (2014) 45:132738. doi: 10.1016/j.humpath.2014.03.003

47. No JH, Sung MW, Hah JH, Choi SH, Lee MC, Kim HS. Prevalence and prognostic value of human papillomavirus genotypes in tonsillar squamous cell carcinoma: a Korean multicenter study. Cancer. (2015) 121:53544. doi: $10.1002 / \mathrm{cncr} .29086$

48. Park WS Ryu J, Cho KH, Choi MK, Moon SH, Yun T. Human papillomavirus in oropharyngeal squamous cell carcinomas in Korea: use of G1 cycle markers as new prognosticators. Head Neck. (2012) 34:140817. doi: 10.1002/hed.21939

49. Song JS, Kim MS, Park JW, Lee YS, Kang CS. Expression of human papillomavirus-related proteins and its clinical implication in tonsillar squamous cell carcinoma Korean. J Pathol. (2012) 46:177-86. doi: 10.4132/KoreanJPathol.2012.46.2.177

50. Kim MJ Ki MS, Kim K, Shim HJ, Hwang JE, Bae WK. Different protein expression associated with chemotherapy response in oropharyngeal cancer according to HPV status. BMC Cancer. (2014) 14:824. doi: 10.1186/1471-2407-14-824

51. Kim Y, Joo YH, Kim MS, Lee YS. Prevalence of high-risk human papillomavirus and its genotype distribution in head and neck squamous cell carcinomas. I Pathol Transl Med. (2020) 54:411-8. doi: $10.4132 /$ jptm.2020.06.22

52. Jung YS, Seok J, Hong S, Ryu CH Ryu J, Jung KW. The emergence of oral cavity cancer and the stabilization of oropharyngeal cancer: recent contrasting epidemics in the South Korean population. Cancer. (2021) 127:1638-47. doi: 10.1002/cncr.33434

53. Dediol E, Sabol I, Virag M, Grce M, Muller D, Manojlovic S, et al. prevalence and p16INKa overexpression in non-smoking non-drinking oral cavity cancer patients. Oral Dis. (2016) 22:517-22. doi: 10.1111/odi.12476

54. Gillison ML, Broutian T, Pickard RK, Tong ZY, Xiao W, Kahle L. Prevalence of oral HPV infection in the United States, 2009-2010. JAMA. (2012) 307:693703. doi: 10.1001/jama.2012.101

55. de Abreu PM, Có AC, Azevedo PL. do Valle IB, de Oliveira KG, Gouvea SA, et al. Frequency of HPV in oral cavity squamous cell carcinoma. BMC Cancer. (2008) 18:324. doi: 10.1186/s12885-018-4247-3

56. Villagómez-Ortíz VJ, Paz-Delgadillo DE, Marino-Martínez I, Ceseñas-Falcón LÁ, Sandoval-de la Fuente A, Reyes-Escobedo A. Prevalence of human papillomavirus infection in squamous cell carcinoma of the oral cavity, oropharynx and larynx. Cir Cir. (2016) 84:363-8. doi: 10.1016/j.circen.2016.08.010

57. Tagliabue M, Mena M, Maffini F, Gheit T, Quirós Blasco B, Holzinger D, et al. Role of human papillomavirus infection in head and neck cancer in Italy: the HPV-AHEAD study. Cancers. (2020) 12:3567. doi: 10.3390/cancers12123567

58. Dahm V, Haitel A, Kaider A, Stanisz I, Beer A, Lill C. Cancer stage and pack-years, but not p16 or HPV, are relevant for survival in hypopharyngeal and laryngeal squamous cell carcinomas. Eur Arch Otorhinolaryngol. (2018) 275:1837-43. doi: 10.1007/s00405-018-4997-1

59. Dogantemur S, Ozdemir S, Uguz A, Surmelioglu O, Dagkiran M, Tarkan O. Assessment of HPV 16, HPV 18, p16 expression in advanced stage laryngeal cancer patients and prognostic significance. Braz J Otorhinolaryngol. (2020) 86:351-7. doi: 10.1016/j.bjorl.2019.11.005

60. Rodrigo JP, Hermsen MA, Fresno MF, Brakenhoff RH, Garcia-Velasco F, Snijders PJ. Prevalence of human papillomavirus in laryngeal and hypopharyngeal squamous cell carcinomas in northern Spain. Cancer Epidemiol. (2015) 39:37-41. doi: 10.1016/j.canep.2014.11.003

61. Stephen JK, Divine G, Chen KM, Chitale D, Havard S, Worsham MJ. Significance of p16 in Site-specific HPV Positive and HPV negative head and neck squamous cell carcinoma. Cancer Clin Oncol. (2013) 2:5161. doi: 10.5539/cco.v2n1p51

62. Marshall DC, Kao DD, Bakst R, Sharma S, Ferrandino R, Rosenzweig K. Prognostic role of human papilloma virus status in hypopharyngeal squamous cell carcinoma. Laryngoscope Investig Otolaryngol. (2020) 5:8607. doi: $10.1002 /$ lio2.443

63. Wendt M, Romanitan M, Nasman A, Dalianis T, Hammarstedt L, Marklund L. Presence of human papillomaviruses and p16 expression in hypopharyngeal cancer. Head Neck. (2014) 36:107-12. doi: 10.1002/hed. 23394

64. Joo YH, Lee YS, Cho KJ, Park JO, Nam IC, Kim CS, et al. Characteristics and prognostic implications of high-risk HPV-associated hypopharyngeal cancers. PLoS ONE. (2013) 8:e78718. doi: 10.1371/journal.pone.0078718

65. Castellsagué X, Alemany L, Quer M, Halec G, Quirós B, Tous S, et al. HPV involvement in head and neck cancers: comprehensive assessment of biomarkers in 3680 patients. J Natl Cancer Inst, (2016) 108:djv403. doi: 10.1093/jnci/djv403

66. Beigh A, Rashi R, Junaid S, Khuroo MS, Farook S. Human papilloma virus (HPV) in sinonasal papillomas and squamous cell carcinomas: a PCR-based study of 60 cases. Gulf J Oncolog. (2018) 1:37-42. Available online at: https:// europepmc.org/article/med/29607821

67. El-Mofty SK, Lu DW. Prevalence of high-risk human papillomavirus DNA in nonkeratinizing (cylindrical cell) carcinoma of the sinonasal tract: a distinct clinicopathologic and molecular disease entity. Am J Surg Pathol. (2005) 29:1367-72. doi: 10.1097/01.pas.0000173240.63073.fe

68. Schlussel Markovic E, Marqueen KE, Sindhu KK, Lehrer EJ, Liu J, Miles B. The prognostic significance of human papilloma virus in sinonasal squamous cell carcinoma. Laryngoscope Investig Otolaryngol. (2020) 5:10708. doi: 10.1002/lio2.468

69. Hu C, Quan H, Yan L, Sun J, Lan L, Wang S. Prevalence of human papillomavirus in sinonasal squamous cell carcinoma with and without association of inverted papilloma in Eastern China. Infect Agent Cancer. (2020) 15:36. doi: 10.1186/s13027-020-00298-4

70. Venuti A, Paolini F, HPV. detection methods in head and neck cancer. Head Neck Pathol. (2012) 6:S63-74. doi: 10.1007/s12105-012-0372-5

71. Nauta IH, Rietbergen MM, van Bokhoven A, Bloemena E, Lissenberg-Witte BI, Heideman DAM. Evaluation of the eighth TNM classification on p16positive oropharyngeal squamous cell carcinomas in the Netherlands and the importance of additional HPV DNA testing. Ann Oncol. (2018) 29:12739. doi: $10.1093 /$ annonc/mdy060

72. Lewis Jr JS, Thorstad WL, Chernock RD, Haughey BH, Yip JH, Zhang Q, et al. p16 positive oropharyngeal squamous cell carcinoma:an entity with a favorable prognosis regardless of tumor HPV status. Am J Surg Pathol. (2010) 34:1088-96. doi: 10.1097/PAS.0b013e3181e84652

Conflict of Interest: The authors declare that the research was conducted in the absence of any commercial or financial relationships that could be construed as a potential conflict of interest.

Publisher's Note: All claims expressed in this article are solely those of the authors and do not necessarily represent those of their affiliated organizations, or those of the publisher, the editors and the reviewers. Any product that may be evaluated in this article, or claim that may be made by its manufacturer, is not guaranteed or endorsed by the publisher.

Copyright (๑) 2022 Jun, Ji, Song, Myung, Park and Tae. This is an open-access article distributed under the terms of the Creative Commons Attribution License (CC BY). The use, distribution or reproduction in other forums is permitted, provided the original author(s) and the copyright owner(s) are credited and that the original publication in this journal is cited, in accordance with accepted academic practice. No use, distribution or reproduction is permitted which does not comply with these terms. 